\title{
The effect of word categorizability on recall by preschoolers and young school children
}

\author{
JAMES W. HALL \\ Northwestern University, Evanston, Ilinois 60201
}

\begin{abstract}
Preschoolers and children in Grades $\mathrm{K}$ and 1 were given five study-recall trials with either categorizable blocked, categorizable unblocked, or uncategorizable word lists. A significant triple interaction reflected a list type effect that occurred only for the school children, and then only on later trials. The preschoolers showed no effect of categorizability, whereas the school children's recall on the final three trials was higher in the categorizable blocked than in the remaining conditions.
\end{abstract}

A number of previous experiments have shown that school children, like adults, recall more items from taxonomically categorizable word lists than from uncategorizable lists. Further, this difference is greater when the category members are blocked during presentation than when they are distributed through the list. Although one might also expect the facilitation effect of categorizability to increase with age, as suggested by Keppel (1964), such an Age by List Type interaction typically has not been found in school children. All three of the above findings were reported in a series of experiments by Cole, Frankel, and Sharp (1971) in which multitrial free recall of 20 familiar nouns was examined. In one study the nouns consisted of five members of each of four categories, presented either in a blocked or an unblocked fashion to children in Grades 1, 3, and 8. Performance improved with age and trials and was better with blocked presentation, but the expected Age by List Type interaction was not found. Nor was it found in a subsequent experiment when either an unblocked categorizable or an uncategorizable list was administered to children in Grades 1, 4,6 , and 9.

Why has the Age by Relatedness interaction not been found in such experiments? Surely the ability of children to capitalize on such interitem relationships does not peak by age 7 or 8 years (see, for example, studies by Moely, Olson, Halwes, \& Flavell, 1969; Neimark, Slotnick, \& Ulrich, 1972; Ornstein, Naus, \& Liberty, 1975). This apparent incongruity is resolved if we assume that by age 7 or 8 years the rate of development of more effective processes for the recall of socalled unrelated words is roughly equivalent to the rate

This research was supported by Grant OEG-5-71-0053 (508) from the Office of Education. Final preparation of this report was completed by the author while a visiting scholar at the Institute of Human Learning, University of California, Berkeley. I am grateful for the various cooperating officials, teachers, and children of the Tom Thumb Nursery School and Public School District 65 in Evanston. Requests for reprints should be sent to James W. Hall, School of Education, Northwestern University, Evanston, Illinois 60201. of development of more effective processes for the recall of categorizable information. (In fact, the fundamental processes involved may be identical, or nearly so, although that possibility cannot be confirmed at this time.) If so, then the unrelated condition is an inappropriate baseline against which to measure developmental changes in the effectiveness of processing related items, i.e., the prediction of an Age by Relatedness interaction no longer is sensible for that particular age range. That interaction, however, would be expected when the youngest subjects examined are at a point of not yet deriving any advantage from the existence of such interitem relationships, and when the oldest subjects are 7 years or older.

Following the above reasoning, the present experiment examined the effects of list categorizability on the multitrial free recall of young school children and of 3- and 4-year-old preschoolers. Based on earlier research (e.g., Cole et al., 1971), a facilitative effect of categorizability on recall was anticipated for the school children. Whether any list categorizability effect on recall would be found for children as young as 3 or 4 years was difficult to predict. Although an item categorizability effect on preschoolers' recall has been claimed, none has been clearly demonstrated. For example, Hagen, Jongeward, and Kail (1975) have interpreted an earlier experiment by Rossi and Rossi (1965) as demonstrating facilitation of recall due to interitem associations among preschoolers. However, that conclusion (not drawn by Rossi and Rossi) is incorrect, since no direct comparison of recall of categorizable vs. uncategorizable items was made in that experiment. A more recent demonstration of better recall for conceptually/associatively related pairs of pictured objects than for unrelated pairs by 2-year-olds (Goldberg, Perlmutter, \& Myers, 1974) also is unconvincing, since specific item difficulty was not controlled and pairs of conceptually related items also were more similar in physical appearance than were the unrelated items (e.g., lollipop and cookie vs. M \& Ms and lion). Given the above ambiguity and the fact that words rather than pictures were used in the present 


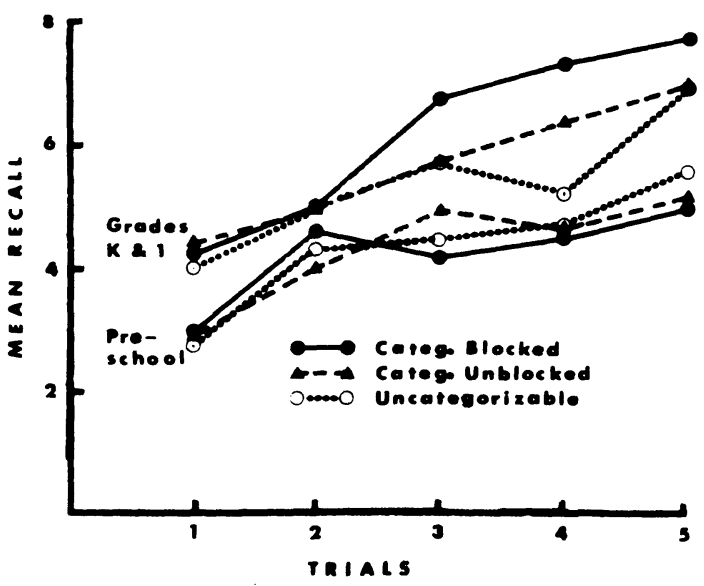

Figure 1. Mean recall as a function of age, list type, and trials.

study, little, if any, effect of categorizability on recall was expected, such that the Age by List Type interaction discussed earlier would be observed.

\section{METHOD}

\section{Subjects}

The preschool group included 27 children at each of ages 3 and 4 years enrolled in an Evanston nursery school and day-care center. The school group consisted of 27 kindergartners and 27 first graders enrolled in a public school in Evanston.

\section{Design}

At each age level, subjects were assigned randomly to one of three list conditions: (1) a list of nine unrelated words, (2) niue words consisting of three instances of each of three categories, with items within a category blocked during presentation, and (3) the same as 2 , but with items in each category distributed rather than blocked. Thus, nine children served in each list condition at each age level. To prevent confounding of particular words with experimental conditions, a pool of 27 words, consisting of three words in each of nine categories, was generated, and a counterbalancing procedure was used to obtain an equal number of appearances of each of the 27 words in each of the three list conditions. The order of words within lists was identical across subjects and across trials. The specific words, blocked by category, were SHIRT, PANTS, HAT; TRUCK, BUS, CAR; KNIFE, FORK, SPOON; WINDOW, DOOR, WALL; DOLLAR, PENNY, NICKEL; YELLOW, BLUE, GREEN; LAKE, RIVER, OCEAN; MOUTH, EARS, NOSE; PIG, COW, HORSE.

\section{Procedure}

The task was administered individually, with the subjects instructed that some words would be read to them and that they were to pronounce each word aloud and think about it so that they would be able to remember it. After a brief practice period, the first study-test trial was given, with the words read at the rate of about one every $5 \mathrm{sec}$. Oral recall was tested after about a 10 -sec delay in which the experimenter chatted casually with the subject. Five such trials were given except where performance was perfect on two consecutive trials, in which case the child was given credit for perfect performances on remaining trials and the session was terminated. The interval between trials was about $20 \mathrm{sec}$.

\section{RESULTS AND DISCUSSION}

An Age (school vs. preschool children) by List Type by Trials analysis of variance showed reliable main effects of both Age $[F(3,96)=9.27, p<.01]$ and Trials $[F(4,384)=71.42, p<.01]$. The mean recall scores, collapsed over Lists and Trials, were 4.40 for the 3-year-olds, 4.27 for the 4-year-olds, 5.28 for the kindergartners, and 6.33 for the first graders. Collapsing over Lists and Age, the mean recall scores increased from 3.57 on Trial 1 to 6.24 on Trial 5. Although both the Age by Trials and the Lists by Trials interactions were marginally reliable $(.10>\mathrm{p}>.05)$, it is the significant second-order interaction of Age by Lists by Trials $[F(24,384)=1.56, p=.05]$ that was most informative. That interaction reflected the fact that list variations led to differential recall only for the older children and that this difference appeared only on the last three trials, when recall for the categorizable blocked condition exceeded that for the remaining conditions. This pattern of results can be seen most clearly in Figure 1, where the two preschool groups are combined, as are the two school groups, in the interest of clearer representation. The superiority of the categorizable blocked condition probably is underestimated, given the fact that 8 out of the 18 school children in that condition recalled all nine items by the final trial.

The results, in short, indicate that the amount and arrangement of conceptual (or associative) relations among to-be-remembered words had no effect with preschoolers, but did influence the young school children after they had had some experience with the list. These results, together with those of other experiments (e.g., Cole et al., 1971) suggest that, from about 4 to 7 years, children's processing effectiveness increases more rapidly for conceptually related than for unrelated words; thereafter the rates of improvement are roughly equivalent for the two types of tasks.

\section{REFERENCES}

Cole, M., Frankel, F., \& Sharp, D. Development of free recall learning in children. Developmental Psychology, 1971, 4, 109-123.

Goldberg, S., Perlmutter, M., \& Myers, N. Recall of related and unrelated lists by 2-year-olds. Journal of Experimental Child Psychology, 1974, 18, 1-8.

Hagen, J. W.. Jongeward, R. H., JR., \& KaIl, R. V., JR. Cognitive perspectives on the development of memory. In H. W. Reese (Ed.), Advances in child development and behavior (Vol. 10). New York: Academic Press, 1975.

KePPEL, G. Verbal learning in children. Psychological Bulletin, $1964,61,63-80$.

Moely, B. E., Olson, F. A., Halwes, T. G., \& Flavell, J. H. Production deficiency in young children's clustered recall. Developmental Psychology, 1969, 1, 26-34.

Neimark, E., Slotnick, N. S., \& Ulrich, T. The development of memorization strategies. Developmental Psychology, 1972, 5, 428-532.

Ornstein, P. A., Naus, M. J., \& Liberty, C. Rehearsal and organizational processes in children's memory. Child Development, 1975, 46, 818-830.

Rossi, E. L., \& Rossi, S. E. Concept utilization, serial order, and recall in nursery-school children. Child Development, 1965, 36, 771-778.

(Received for publication June 14, 1976.) 